\title{
Vaginal Delivery and Maternal Knowledge on Correct Breastfeeding Initiation Time as Predictors of Early Breastfeeding Initiation: Lesson from a Community-Based Cross-Sectional Study
}

\begin{abstract}
Abdulbasit Musa Seid
Department of Midwifery, College of Health and Medical Sciences, Haramaya University, P.O. Box 235, Harar, Ethiopia

Correspondence should be addressed to Abdulbasit Musa Seid; atinaf.musa2@gmail.com

Received 10 October 2013; Accepted 8 December 2013; Published 21 January 2014

Academic Editors: S. Pinney and M. J. Toole

Copyright (C) 2014 Abdulbasit Musa Seid. This is an open access article distributed under the Creative Commons Attribution License, which permits unrestricted use, distribution, and reproduction in any medium, provided the original work is properly cited.

Background. Early initiation of breastfeeding is a recommended practice by the World Health Organization (WHO), but in Ethiopia only $52 \%$ of the mothers practiced early initiation of breastfeeding. Hence, this study aimed to assess prevalence of early initiation of breastfeeding and the associated factors among mothers in Bahir Dar City, northwest Ethiopia. Methods. A community-based cross-sectional study was conducted among mothers who delivered 12 months before the study began in Bahir Dar City, northwest Ethiopia. A cluster sampling technique was used to select a sample of 819 participants. Bivariate and multivariate analyses were performed. Results. In this study, the prevalence of early initiation was found to be $87.0 \%$. On multivariate logistic regression, delivering vaginally $(\mathrm{AOR}=7.37,95 \% \mathrm{CI}=4.24,13.82)$ and being knowledgeable on correct initiation time $(\mathrm{AOR}=6.08,95 \% \mathrm{CI}=$ $3.71,9.95)$ were found to be independent predictors of early initiation.Conclusions. Prevalence of early initiation of breastfeeding in Bahir Dar city is relatively good but still lower than the national plan. Delivering vaginally and being knowledgeable on correct initiation time were significantly associated with early initiation. Increasing maternal knowledge on correct initiation and providing adequate pain relief and early assistance for mothers who gave birth by $\mathrm{C} / \mathrm{S}$ were recommended.
\end{abstract}

\section{Background}

Breastfeeding (BF) is an unequalled way of providing ideal food for the healthy growth and development of infants [1]. As per the WHO recommendation, breastfeeding should be initiated early and exclusive breastfeeding should be continued for the first six months of life to achieve optimal growth, development, and health [2-4].

A report from Ghana indicated that the risk of death as a result of infection increased with increasing delay in initiation of breastfeeding; overall late initiation was associated with a 2.6-fold risk [5]. Another study also reported the importance of early breastfeeding initiation in reducing neonatal mortality [6]. Additionally, early initiation of breastfeeding and continued EBF for the first six months have been found to have beneficial effect in improving vaccine response [7].
Malnutrition has been responsible for about $45 \%$ of 6.6 million deaths annually among children under five worldwide. The vast majority of this malnutrition related deaths are often associated with inappropriate feeding practices [8]. Global risk assessment of suboptimal breastfeeding indicates that $96 \%$ of all infant deaths in developing countries that are attributable to inappropriate feeding occur during the first six months of life [9].

By recognizing the undeniable role of early breastfeeding initiation in reducing child mortality, the Ethiopian Ministry of Health had targeted an increase in the proportion of newborn put to breast within the first hour of life to 92 percent by 2015 as one strategy to improve child health [10]. But, the 2011 Ethiopian Demographic and Health Survey (EDHS) showed the proportion of children who were put to breast within the first hour of life as 52\% [11] which is 
even lower (69\%) compared to 2005 EDHS [12]. So, assessing the factors associated with early initiation of breastfeeding is crucial to make interventions that speed up the government efforts and decrease infants' morbidity and mortality.

\section{Methods}

Ethiopia is the second most populous country in sub-Saharan Africa with a population of about 85 million and it is one of the world's oldest civilizations. The economy of Ethiopia is largely depending on agriculture. Economic growth brought with it positive trends in reducing poverty, in both urban and rural areas. By 2010 only $29.6 \%$, were found to be under extreme poverty as measured by the national poverty line, with less than $\$ 0.6$ (12 Ethiopian birr) per day [13].

This community-based cross-sectional study was carried out from June 10 to 25,2012, among mothers who delivered 12 months before the study began in Bahir Dar City, Northwest Ethiopia. Bahir Dar City, the capital of Amhara Regional State, is located $565 \mathrm{~km}$ northwest of Addis Ababa, the capital of Ethiopia. In Bahir Dar City, there are 9 city kebeles, the smallest administrative unit. Based on 2007 national population census, the town has a total of $180,094(87,089$ male and 93,005 female) population. Out of this, females in the reproductive age groups (15-49 years) were 39,800 . In the town, the expected number of pregnancies in a year is 6,843 with the expected live births of 6,483 . The number of households in the town is 37,519 [14].

To select study participants, a cluster sampling technique was used. Four kebeles were selected from 9 kebeles in the town using a simple random sampling technique. Sample size was determined by using a single population proportion formula considering the following assumptions: proportion of early initiation, 52\% taken from 2011 EDHS [11]; 95\% level of confidence $(Z=1.96) ; 5 \%$ marginal error. The final sample size was adjusted using the design effect of 2 and $5 \%$ nonresponse rate. Thus, the sample size required was 807 , but with all participants in each cluster included, a final sample size of 819 was achieved.

Data on sociodemographic information, obstetric factors like parity, child and breast feeding practice factors, and maternal knowledge on timely initiation were collected using a pretested and structured questionnaire. Data were collected, after training was given to both data collectors and supervisors, through face-to-face interview. Data were entered into EPI Info version 3.5.1 and exported to SPSS version 20.0 software package for analysis. The results were presented in the form of tables, figures, and text using frequencies and summary statistics such as mean, standard deviation, and percentage to describe the study population in relation to relevant variables. The data were analyzed using logistic regression to determine the effect of various factors on the outcome variable and to control confounding. Most of the variables were fitted to the bivariate logistic regression. Then all variables having $P$ value $\leq 0.2$ in the bivariate analysis were further entered into multivariate logistic regression model. Variables having $P$ value $\leq 0.05$ in the multivariate analysis were taken as significant predictors. Crude and adjusted odds ratios with their $95 \%$ confidence intervals were calculated. The Hosmer and Lemeshow goodness-of-fit test was used to assess whether the necessary assumptions for the application of multiple logistic regression were fulfilled and $P$ value $>0.05$ was considered a good fit.

Early initiation of breastfeeding was defined as proportion of children who were put to the breast within one hour of birth, whereas Prelacteal feeding was defined as the proportion of children who receive anything to drink other than breast milk in the first three days of life. Colostrum feeding was also defined as the proportion of infants who receive the first milk [1]. Maternal knowledge on correct early breastfeeding initiation time was asked by asking this open ended question "when mothers should first put their new born to breast?" Those mothers who responded by saying within one hour of delivery were considered to be knowledgeable.

Ethical clearance was obtained from institution review board of College of Medicine and Health Sciences, University of Gondar. A formal letter of cooperation was written to Bahir Dar City health office and the respective kebeles. Voluntary verbal consent was obtained from each study participant.

\section{Results}

3.1. Sociodemographic Characteristics of the Participants. All 819 mothers in the selected clusters were included in the analysis giving a response rate of $100 \%$. The mean age of the mothers was 26.1 years ( $\mathrm{SD} \pm 4.5$ years), whereas the median age of the infants was 7 months (IQR $=5$ months). The majority (748 91.3\%) of the mothers were married, 628 (76.7\%) were Orthodox Christian by religion, 801 (97.8\%) were Amhara by ethnicity, and 493 (60.2\%) were housewife by occupation. Two hundred sixty-one (31.9\%) and 177 (21.6\%) of the mothers and fathers did not attend formal education, respectively. Regarding average monthly income of the participants, 214 (26.1\%) of the households have monthly income of less than 700 Ethiopian birr. Seven hundred forty-nine (91.5\%) of the participants have radio or television in their house. Almost all 809 (98.8\%) of the participants were not cigarette smokers.

Regarding infants, 445 (54.3\%) were females, 360 (44\%) were first borns, and $536(65.4 \%)$ were six months of age or more at time of data collection (Table 1).

3.2. Obstetric Characteristics of the Participants. Of all participants, more than half (55.9\%) were multiparous. Most of the respondents (94.9\%) had ANC follow-up with a mean frequency of ANC visits of 3.7 (SD \pm 0.7 ) but $184(23.6 \%)$ were not counseled on breastfeeding during their ANC followup. Regarding place of delivery, 742 (90.6\%) delivered their youngest child at health institutions. Seven hundred and twenty-eight $(88.9 \%)$ of the mothers delivered vaginally, and 611 (82.3\%) of the mothers who delivered at health institutions were counseled on breastfeeding (Table 2).

3.3. Breastfeeding Practices. Almost all 815 (99.5\%) children were ever breastfed at some point in the past. Of those who 
TABLE 1: Sociodemographic characteristics of the mothers with their infants $(n=819)$ among mothers who gave birth in the last 12 months in Bahir Dar City, Northwest Ethiopia, June 2012.

\begin{tabular}{|c|c|}
\hline Variables & Frequency (\%) \\
\hline \multicolumn{2}{|l|}{ Maternal age (in year) } \\
\hline $17-19$ & $19(2.3)$ \\
\hline $20-34$ & $751(91.7)$ \\
\hline $35+$ & $49(6.0)$ \\
\hline \multicolumn{2}{|l|}{ Infants age (in months) } \\
\hline $0-1$ & $31(3.8)$ \\
\hline $2-3$ & $113(13.8)$ \\
\hline $4-5$ & $139(17.0)$ \\
\hline 6 and above & $536(65.4)$ \\
\hline \multicolumn{2}{|l|}{ Sex of the infants } \\
\hline Male & $445(54.3)$ \\
\hline Female & $374(45.7)$ \\
\hline \multicolumn{2}{|l|}{ Birth order of the infants } \\
\hline First born & $360(44.0)$ \\
\hline 2nd to 4 th & $438(53.5)$ \\
\hline 5th and above & $21(2.6)$ \\
\hline \multicolumn{2}{|l|}{ Marital status } \\
\hline Married & $748(91.3)$ \\
\hline Divorced & $34(4.2)$ \\
\hline Widowed/single/separated & $37(4.5)$ \\
\hline \multicolumn{2}{|l|}{ Religion } \\
\hline Orthodox & $628(76.7)$ \\
\hline Muslim & $178(21.7)$ \\
\hline Protestant/Adventist & $13(1.6)$ \\
\hline \multicolumn{2}{|l|}{ Ethnicity } \\
\hline Amhara & $801(97.8)$ \\
\hline Others (Agaw, Tigre, Oromo) & $18(2.2)$ \\
\hline \multicolumn{2}{|l|}{ Occupation of the mothers } \\
\hline Housewife & $493(60.2)$ \\
\hline Government employer & $150(18.3)$ \\
\hline Private work & $62(7.6)$ \\
\hline Daily laborer & $101(12.3)$ \\
\hline Others (farmer/students) & $13(1.6)$ \\
\hline \multicolumn{2}{|l|}{ Maternal education } \\
\hline No formal education & $261(31.9)$ \\
\hline Primary education & $161(19.7)$ \\
\hline Secondary education & $198(24.2)$ \\
\hline Tertiary education & $199(24.3)$ \\
\hline \multicolumn{2}{|l|}{ Husband education } \\
\hline No formal education & $177(21.6)$ \\
\hline Primary education & $149(18.2)$ \\
\hline Secondary education & $204(24.9)$ \\
\hline Tertiary education & $289(35.3)$ \\
\hline \multicolumn{2}{|l|}{ Average monthly income } \\
\hline $100-700$ & $214(26.1)$ \\
\hline $701-1200$ & $207(25.3)$ \\
\hline $1201-2000$ & $200(24.4)$ \\
\hline $2000-20,000$ & $198(24.2)$ \\
\hline \multicolumn{2}{|l|}{ Access to media (radio or TV) } \\
\hline Yes & $749(91.5)$ \\
\hline No & $70(8.5)$ \\
\hline \multicolumn{2}{|l|}{ Maternal smoking } \\
\hline Yes & $10(1.2)$ \\
\hline No & $809(98.8)$ \\
\hline
\end{tabular}

TABLE 2: Obstetric characteristics of participants $(n=819)$ in Bahir Dar City, Northwest Ethiopia, June 2011.

\begin{tabular}{lc}
\hline Variable & $\begin{array}{c}\text { Frequency } \\
(\%)\end{array}$ \\
\hline Parity & $361(44.1)$ \\
$\quad$ Primiparous & $458(55.9)$ \\
Multiparous & \\
Presence of ANC & $777(94.9)$ \\
$\quad$ Yes & $42(5.1)$ \\
No & \\
Frequency of ANC $(N=777)$ & $240(30.9)$ \\
$1-3$ visits & $537(69.1)$ \\
4 visits and above & $593(76.4)$ \\
Counseling on BF at ANC $(N=777)$ & $184(23.6)$ \\
$\quad$ Yes & \\
No & $742(90.6)$ \\
Delivery place & $77(9.4)$ \\
Health facility & \\
Home & \\
BF counseling at health facility during delivery & \\
(N $=742)$ & \\
Yes & \\
No & \\
Mode of delivery & $131(17.7)$ \\
Vaginal delivery & \\
C/S delivery & \\
\hline
\end{tabular}

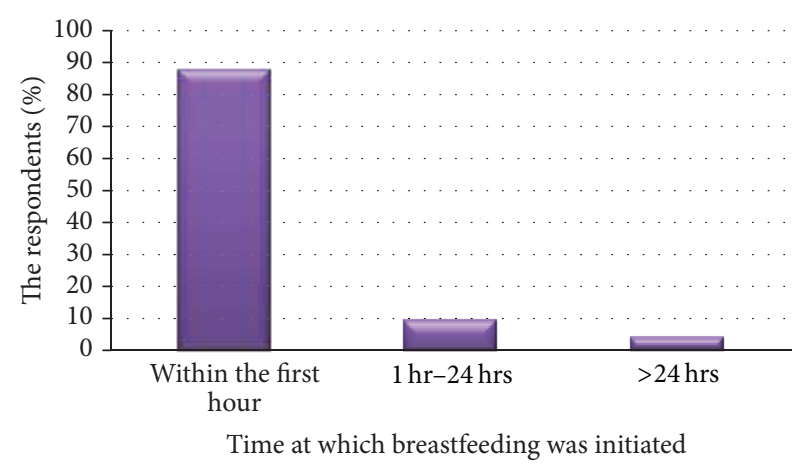

FIgURE 1: Distribution of mothers by the time they first put their newborn to breast in Bahir Dar City, Northwest Ethiopia.

were ever breastfed, $709(87.0 \%)$ of the mothers initiated breastfeeding within one hour of birth while, only $32(3.9 \%)$ of respondents initiated breastfeeding after the first day of life (Figure 1).

From all those who had ever breastfed, 679 (83.3\%) had fed colostrums and $220(27.0 \%)$ of mothers gave one or more Prelacteal feed. Ninety-seven (11.9\%) of the participants reported to have breast related problems that create difficulty in feeding their infants. Seven hundred and sixty (93.5\%) of the participants received infant feeding counseling/advice 
TABLE 3: Breastfeeding practice and knowledge of the respondents on timely initiation of breastfeeding $(n=819)$ in Bahir Dar City, Northwest Ethiopia, June 2012.

\begin{tabular}{lc}
\hline Variables & Frequency $(\%)$ \\
\hline Ever breastfeeding & $815(99.5)$ \\
$\quad$ Yes & $4(0.5)$ \\
No & \\
Initiation time $(n=815)$ & $709(87.0)$ \\
$\quad$ Within one hour of birth & $106(13.0)$ \\
$\quad$ After one hour of birth & \\
Colostrums discarded $(n=815)$ & $136(16.7)$ \\
Yes & $679(83.3)$ \\
No & \\
Prelacteal feeding $(n=815)$ & $220(27.0)$ \\
Yes & $595(73.0)$ \\
No & \\
Breastfeeding difficulty & $97(11.9)$ \\
Yes & $718(89.1)$ \\
No & \\
Exclusive breastfeeding practice & $412(50.3)$ \\
Yes & $407(49.7)$ \\
No & \\
Know early initiation time & $661(80.7)$ \\
Yes & $158(19.3)$ \\
No & \\
Received infant feeding advice/counseling & \\
Yes & \\
No & \\
\hline
\end{tabular}

from different sources such as health professionals other than health extension workers 704 (91.1\%), media 321 (41.91\%), health extension workers 24 (3.13\%), and family members 28 (3.59\%). Regarding prevalence of EBF, computed using since birth dietary recall method, 412 (50.3\%) of the participants practiced EBF appropriate to their age (Table 3 ).

\subsection{Factors Associated with Early Initiation of Breastfeed-} ing. On bivariate analysis, having average income range of 1,201 to 2,000 Ethiopian birr, having ANC follow-up during last pregnancy, delivering last birth vaginally, and being knowledgeable on correct initiation time were found to have significant association with early initiation of breast feeding.

Those mothers with income range of 1201 to 2000 Ethiopian birr were $51 \%(\mathrm{COR}=0.49,95 \% \mathrm{CI}=0.27,0.89)$ less likely to initiate breastfeeding early compared to those mothers with income range of 100-700 Ethiopian Birr. In addition, mothers who had ANC during their last pregnancy were 3 times $(\mathrm{COR}=2.9995 \% \mathrm{CI}=1.48,6.07)$ more likely to initiate breast feeding early than those who had not.

Regarding mode of delivery, those mothers who delivered their last child vaginally were 5 times $(\mathrm{COR}=5.17,95 \% \mathrm{CI}$ $3.16,8.46)$ more likely to initiate breastfeeding early than those delivered by C/S. Furthermore, those mothers who were Knowledgeable on correct time of initiation were 5 times
$(\mathrm{COR}=4.78,95 \% \mathrm{CI}, 3.10,7.38)$ more likely to initiate breast feeding early than those who were not knowledgeable.

On multivariate analysis only two variables, that is, mode of delivery and knowledge on correct initiation time, were found to be the predictors of early initiation of breastfeeding.

Those mothers who delivered their last child vaginally were 7.4 times $(\mathrm{AOR}=7.37,95 \% \mathrm{CI}=4.24,13.82)$ more likely to initiate breastfeeding early than those who delivered by $\mathrm{C} / \mathrm{S}$. In addition, those mothers who were knowledgeable on correct time of breastfeeding initiation were 6.1 times $(\mathrm{AOR}=$ $6.08,95 \% \mathrm{CI}=3.71,9.95)$ more likely to initiate breastfeeding early than those who were not knowledgeable (Table 4).

\section{Discussion}

World Health Organization and national infant and child health feeding guide line recommend early initiation of breastfeeding within the first hour of life [1]. This intervention, that is, early breastfeeding initiation, was found to have significant contribution to reducing neonatal mortality and morbidity [5].

In this study, the prevalence of early initiation was found to be $709(87 \%)$. This finding is higher than that of EDHS report of 2011 (52\%) and the study from Goba, Ethiopia $(52.4 \%)$ [11, 15]. This high prevalence of early initiation compared to the afore mentioned Ethiopian studies might be due to the fact that this study was conducted in urban area while the previous studies were conducted in both urban and rural areas. This finding can also be supported by EDHS of 2011 [11] which showed high initiation rate among urban dwellers compared to rural.

Similarly, this finding was higher than that of Tanzania (46.1\%), Malawi (37\%), Niger (8\%), Saudi Arabia (11.4\%), Qatar (57\%), India (22\%), Turkey (35.2\%), south Nepal (3.4), Pokhara municipality of Nepal (43.5\%), and Brazil (47.1\%) [16-25]. This might be due to crosscultural difference in breastfeeding.

Concerning prelacteal feeding, 220 (27\%) of the respondents provide one or more prelacteal feeds to their newborn within the first three days of life. This finding was similar to EDHS report of 2011 [11] but lower than that of the studies conducted in Egypt (36.7\%) and India (36.4\%) [26, 27]. This crosscountry difference might be again due to the crosscultural difference of the population.

In this study, mode of delivery and maternal knowledge on correct initiation time were found to be independent predictors of early breastfeeding initiation by multivariate analysis.

Those mothers who delivered their last child Vaginally were 7.4 times more likely to initiate breastfeeding early than those who gave birth by $\mathrm{C} / \mathrm{S}$. This finding was in agreement with the study from Turkey, Brazil, India, Nigeria, Saudi Arabia, and China [22, 25, 27-30]. This might be due to the fact that $\mathrm{C} / \mathrm{S}$ related pain and discomfort may prevent mothers from practicing early initiation of breastfeeding.

In this study, those mothers who were knowledgeable on correct time of breastfeeding initiation were 6.1 times more likely to practice early initiation than those who were 
TABLE 4: Bivariate and multivariate analysis of factors associated with early initiation of breastfeeding among mothers who gave birth in the last 12 months in Bahir Dar City, June 2012.

\begin{tabular}{|c|c|c|c|c|}
\hline \multirow{2}{*}{ Variable } & \multicolumn{2}{|c|}{ Timely initiation } & \multirow{2}{*}{ Crude odds ratio (95\% CI) } & \multirow{2}{*}{ Adjusted odds ratio (95\% CI) } \\
\hline & Yes $n(\%)$ & No $n(\%)$ & & \\
\hline \multicolumn{5}{|l|}{ Average family income } \\
\hline $100-700$ & $195(91.1)$ & $19(8.9)$ & 1 & \\
\hline $701-1200$ & $181(87.9)$ & $25(12.1)$ & $0.71(0.38,1.32)$ & $0.64(0.32,1.27)$ \\
\hline $1201-2000$ & $167(83.5)$ & $33(16.5)$ & $0.49(0.27,0.89)$ & $0.50(0.26,0.98)$ \\
\hline $2001-20,000$ & $166(85.1)$ & $29(14.9)$ & $0.56(0.30,1.03)$ & $0.55(0.27,1.09)$ \\
\hline \multicolumn{5}{|l|}{ ANC visit } \\
\hline Yes & $680(87.9)$ & $94(12.1)$ & $2.99(1.48,6.07)$ & $2.21(0.98,5.0)$ \\
\hline No & $29(70.7)$ & $12(29.3)$ & 1 & \\
\hline \multicolumn{5}{|l|}{ Mode of delivery } \\
\hline Vaginal & $652(89.9)$ & $73(10.1)$ & $5.17(3.16,8.46)$ & $7.37(4.24,13.82)^{*}$ \\
\hline $\mathrm{C} / \mathrm{S}$ & $57(63.3)$ & $33(36.7)$ & 1 & \\
\hline \multicolumn{5}{|c|}{ Knowledge of correct initiation time } \\
\hline Knowledgeable & $601(91.3)$ & $57(8.7)$ & $4.78(3.10,7.38)$ & $6.08(3.71,9.95)^{*}$ \\
\hline Not knowledgeable & $108(68.8)$ & 49 (31.2) & 1 & \\
\hline
\end{tabular}

${ }^{*}$ Significant at $P$ value of $\leq 0.05$.

not knowledgeable. This finding is similar to the American study [31] which indicates the importance of breastfeeding knowledge on early initiation of breastfeeding. This suggests the importance of maternal knowledge on correct initiation time in improving early initiation of breastfeeding.

Limitations. Recall bias might be introduced, as the mothers might not have recalled accurately when they initiated breastfeeding. This may under- or overestimate the true prevalence of early initiation. It is also difficult to establish temporal relationship as the study design was cross-sectional. Despite these limitations, the findings from this study will contribute to the understanding of the factors associated with early initiation of breastfeeding in the study area.

\section{Conclusions}

Prevalence of early initiation of breastfeeding in Bahir Dar City is relatively good but still lower than the national plan. Delivering vaginally and being knowledgeable on correct initiation time were significantly associated with early breastfeeding initiation. Increasing maternal knowledge on correct initiation time by educating the mothers both at community and institutional levels and providing adequate pain relief and early assistance for mothers who gave birth by $\mathrm{C} / \mathrm{S}$ were recommended in order to increase the proportion of women practicing early initiation of breastfeeding.

\section{Abbreviations}

ANC: Antenatal care

BF: Breastfeeding

EBF: Exclusive breastfeeding

EDHS: Ethiopian Demographic and Health Survey

C/S: Caesarean section

WHO: World Health Organization.

\section{Conflict of Interests}

The author declares that there is no conflict of interests regarding the publication of this paper.

\section{Authors' Contribution}

Abdulbasit Musa designed the study, performed the statistical analysis, and drafted the paper.

\section{Acknowledgments}

The authors very grateful to the University of Gondar for their technical and financial support of this study and would like to thank all mothers who participated in this study for their commitment in responding to interviews.

\section{References}

[1] WHO, Global Strategy for Infant and Young Child Feeding, Geneva, Swizerland, 2003.

[2] WHO, "The optimal duration of exclusive breastfeeding," Report of an Expert Consultation, World Health Organization, Department of Nutrition for Health and Development and Department of Child and Adolescent Health and Development, Geneva, Switzerland, 2001.

[3] WHO, "Breast feeding early initiation," http://www.who.int/ nutrition/topics/world_breastfeeding_week/en/.

[4] Federal Ministry of Health, National Strategy for Infant and Young Child Feeding (IYCF), Federal Ministry of Health, Family Health Department, Addis Ababa, Ethiopia, 2004.

[5] K. M. Edmond, B. R. Kirkwood, S. Amenga-Etego, S. OwusuAgyei, and L. S. Hurt, "Effect of early infant feeding practices on infection-specific neonatal mortality: an investigation of the causal links with observational data from rural Ghana," American Journal of Clinical Nutrition, vol. 86, no. 4, pp. 11261131, 2007. 
[6] Z. A. Bhutta, Z. S. Lassi, A. Blanc, and F. Donnay, "Linkages among reproductive health, maternal health, and perinatal outcomes," Seminars in Perinatology, vol. 34, no. 6, pp. 434-445, 2010.

[7] J. G. Dòrea, "Breastfeeding is an essential complement to vaccination," Acta Paediatrica, vol. 98, no. 8, pp. 1244-1250, 2009.

[8] WHO, Children: reducing mortality, http://www.who.int/mediacentre/factsheets/fs178/en/.

[9] J. A. Lauer, A. P. Betrán, A. J. D. Barros, and M. De Onís, "Deaths and years of life lost due to suboptimal breast-feeding among children in the developing world: a global ecological risk assessment," Public Health Nutrition, vol. 9, no. 6, pp. 673-685, 2006.

[10] Federal Minstry of Health, Health Sector Developement Program IV Woreda Based Annual Core Plan, Addis Ababa, Ethiopia, 2010.

[11] Central Statistical Agency, Ethiopia Demographic and Health Survey 2011, Addis Ababa, Ethiopia, 2012.

[12] Central Statistical Agency and ORC Macro, Ethiopia Demographic and Health Survey (EDHS) 2005, Central Statistical Agency and ORC Macro, Addis Ababa, Ethiopia, 2006.

[13] The World Bank, Ethiopia Overview, http://www.worldbank .org/en/country/ethiopia/overview.

[14] Fedral Democratic Republic of Ethiopia, Census Commission: Summary and Statistical Report of the 2007 Population and Housing Census, Addis Ababa, Ethiopia, 2008.

[15] T. Setegn, M. Gerbaba, and T. Belachew, "Determinants of timely initiation of breastfeeding among mothers in Goba Woreda, South East Ethiopia: a cross sectional study," BMC Public Health, vol. 11, article 217, 2011.

[16] R. Victor, S. K. Baines, K. E. Agho, and M. J. Dibley, "Determinants of breastfeeding indicators among children less than 24 months of age in Tanzania: a secondary analysis of the 2010 Tanzania Demographic and Health Survey," BMJ Open, vol. 3, no. 1, 2013.

[17] L. N. Kazembe, "Spatial modelling of initiation and duration of breastfeeding: analysis of breastfeeding behaviour in MalawiI," World Health \& Population, vol. 10, no. 3, pp. 14-31, 2008.

[18] M. O. Oche and A. S. Umar, "Breastfeeding practices of mothers in a rural community of Sokoto, Nigeria," The Nigerian postgraduate medical journal, vol. 15, no. 2, pp. 101-104, 2008.

[19] A.-H. El-Gilany, B. Sarraf, and A. Al-Wehady, "Factors associated with timely initiation of breastfeeding in al-hassa province, Saudi Arabia," Eastern Mediterranean Health Journal, vol. 18, no. 3, pp. 250-254, 2012.

[20] S. Al-Kohji, H. A. Said, and N. A. Selim, "Breastfeeding practice and determinants among Arab mothers in Qatar," Saudi Medical Journal, vol. 33, no. 4, pp. 436-443, 2012.

[21] A. Laxmaiah, K. Venkaiah, and G. N. V. Brahmam, "Impact of feeding and breastfeeding practices on the nutritional status of infants in a district of Andhra Pradesh, India," The National Medical Journal of India, vol. 25, no. 4, pp. 201-206, 2012.

[22] E. Orun, S. S. Yalçin, Y. Madendağ, Z. Üstünyurt-Eras, Ş. Kutluk, and K. Yurdakök, "Factors associated with breastfeeding initiation time in a baby-friendly hospital," Turkish Journal of Pediatrics, vol. 52, no. 1, pp. 10-16, 2010.

[23] L. C. Mullany, J. Katz, Y. M. Li et al., "Breast-feeding patterns, time to initiation, and mortality risk among newborns in Southern Nepal," Journal of Nutrition, vol. 138, no. 3, pp. 599603, 2008.
[24] S. H. Subba, T. S. Chandrashekhar, V. S. Binu, H. S. Joshi, M. S. Rana, and S. B. Dixit, "Infant feeding practices of mothers in an urban area in Nepal," Kathmandu University Medical Journal, vol. 5, no. 17, pp. 42-47, 2007.

[25] T. O. Vieira, G. O. Vieira, E. R. J. Giugliani, C. M. Mendes, C. C. Martins, and L. R. Silva, "Determinants of breastfeeding initiation within the first hour of life in a Brazilian population: cross-sectional study," BMC Public Health, vol. 10, article 760, 2010.

[26] S. A. Sallam, G. M. Babrs, R. R. Sadek, and A. M. Mostafa, "Knowledge, attitude, and practices regarding early start of breastfeeding among pregnant, lactating women and healthcare workers in el-minia university hospital," Breastfeeding Medicine, vol. 8, no. 3, pp. 312-316, 2013.

[27] A. Patel, A. Banerjee, and A. Kaletwad, "Factors Associated with Prelacteal Feeding and Timely Initiation of Breastfeeding in Hospital-Delivered Infants in India," Journal of Human Lactation, vol. 29, no. 4, pp. 572-578, 2013.

[28] D. D. Awi and E. A. Alikor, "Barriers to timely initiation of breastfeeding among mothers of healthy full-term babies who deliver at the University of Port Harcourt Teaching Hospital," Nigerian journal of clinical practice, vol. 9, no. 1, pp. 57-64, 2006.

[29] T. Amin, H. Hablas, and A. A. Al Qader, "Determinants of initiation and exclusivity of breastfeeding in al Hassa, Saudi Arabia," Breastfeeding Medicine, vol. 6, no. 2, pp. 59-68, 2011.

[30] S. Guo, X. Fu, R. W. Scherpbier et al., "Breastfeeding rates in central and western China in 2010: implications for child and population health," Bulletin of the World Health Organization, vol. 91, no. 5, pp. 322-331, 2013.

[31] M. Kornides and P. Kitsantas :, "Evaluation of breastfeeding promotion, support, and knowledge of benefits on breastfeeding outcomes," Journal of Child Health Care, vol. 17, no. 3, pp. 264273, 2013. 


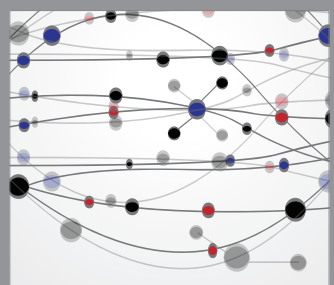

The Scientific World Journal
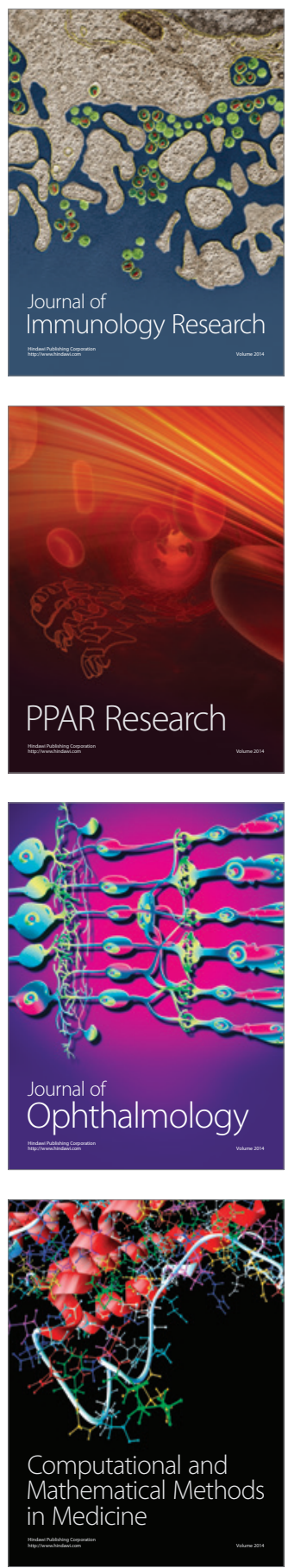

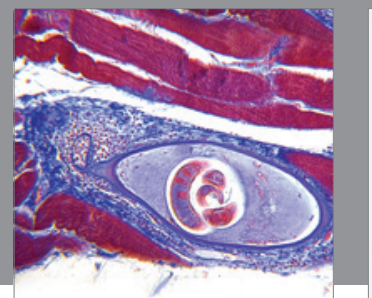

Gastroenterology

Research and Practice
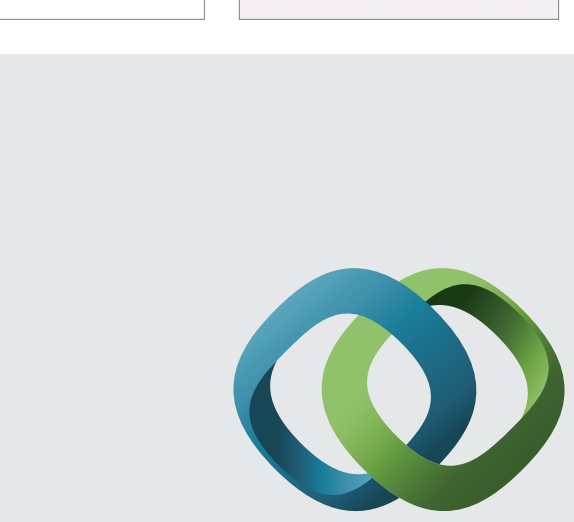

\section{Hindawi}

Submit your manuscripts at

http://www.hindawi.com
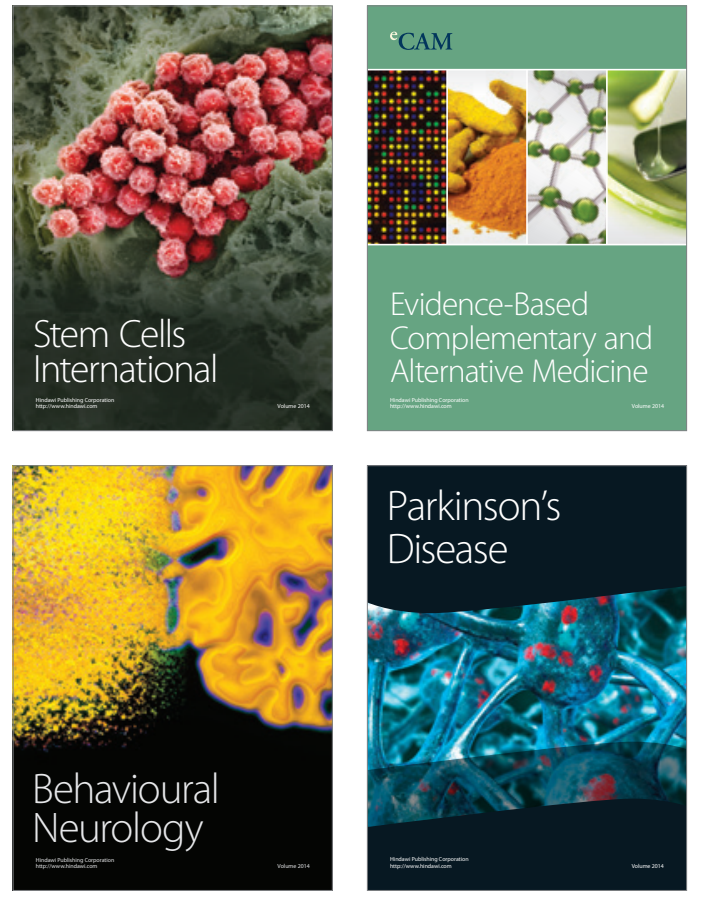
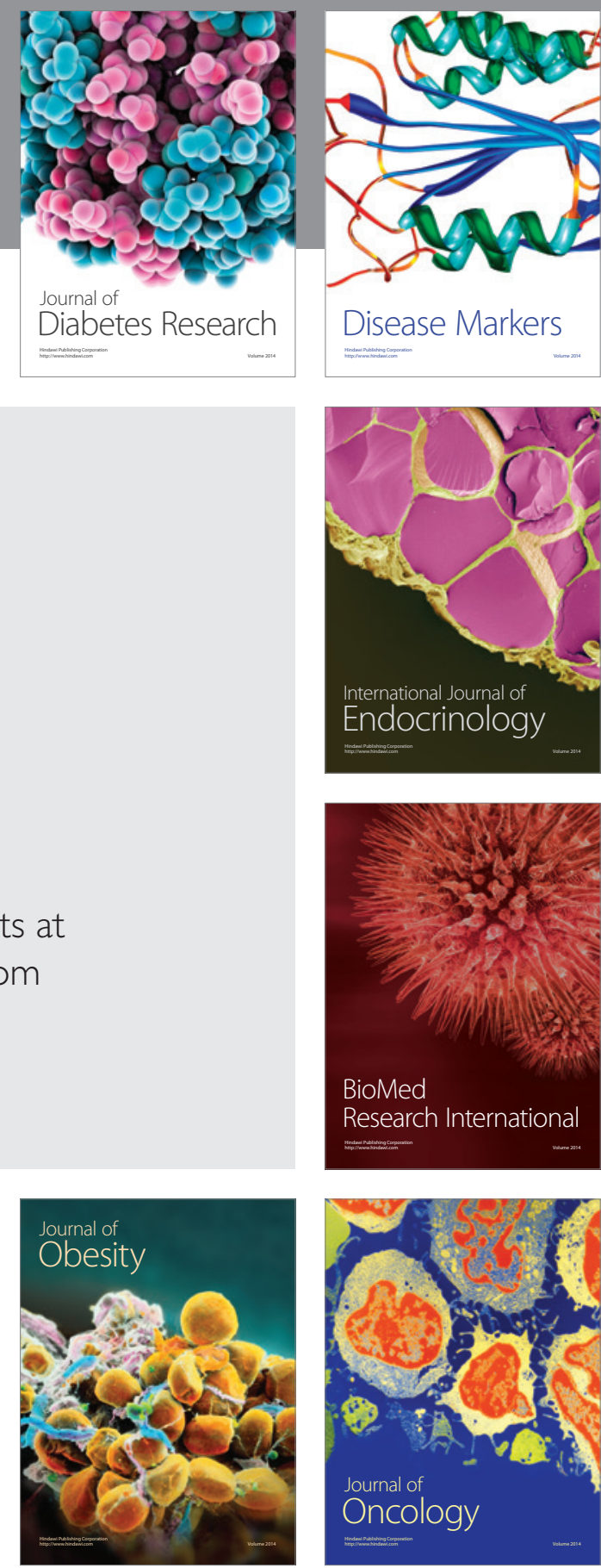

Disease Markers
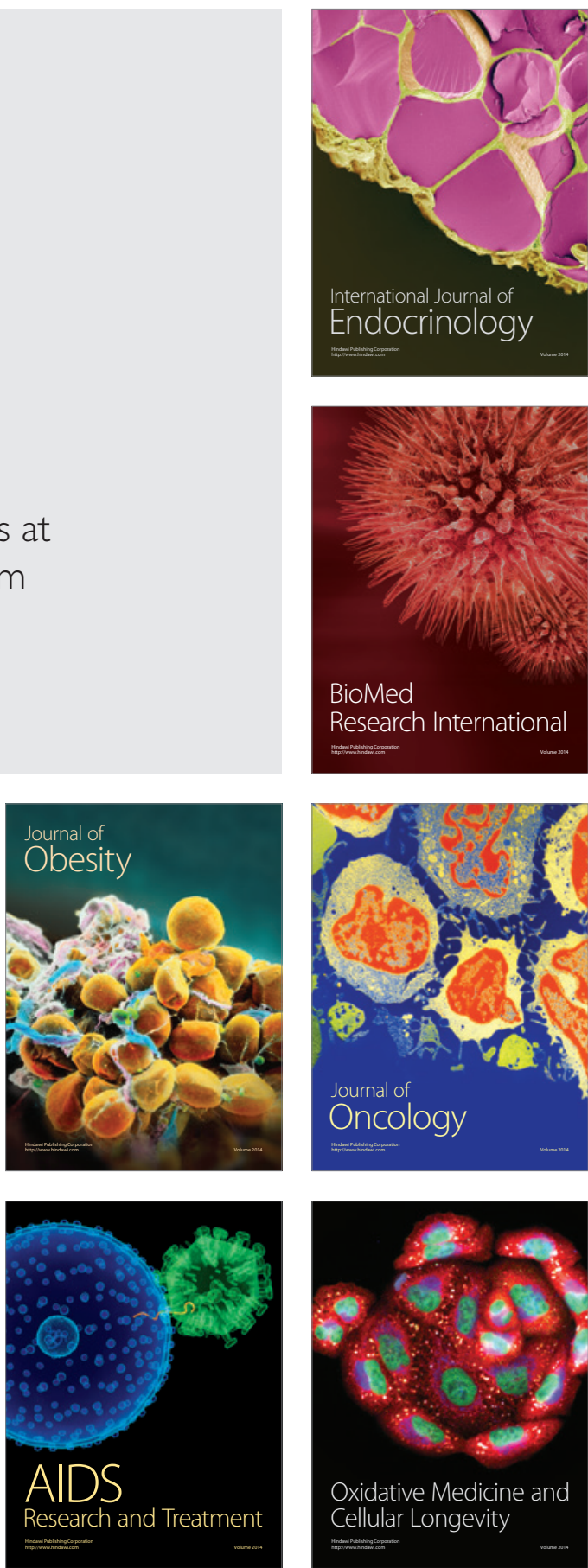